DOI: $10.24234 /$ se.v5i1.288

\title{
HOW VISUALLY IMPAIRED LEARNERS CONSTRUCT OPPORTUNITIES TO LEARN MATHEMATICS?
}

\author{
AUTHORS' DATA \\ Setseetso Matobako (Doctoral candidate) \\ University of the Free State, South Africa, Republic of South Africa \\ Contacts: setseetso@gmail.com \\ Loyiso C. Jita, $\mathrm{PhD}$ in Curriculum, Professor \\ Teaching and Education Policy (Science Education), \\ SANRAL Chair in Mathematics, Natural Sciences and Technology Education \\ University of the Free State, South Africa, Republic of South Africa \\ Contacts: jitalc@ufs.ac.za
}

\begin{abstract}
Many studies view inclusive education practices as having the potential to improve equal access to education, where the existing barriers are reduced. In mathematics specifically, it is believed that providing more opportunities to learn for learners with special educational needs can improve their performance and result in scaling down the mathematics achievement gap. A differing perspective from recent empirical research that focused on mathematics instruction involving learners with special educational needs in regular classroom settings, however, found that these learners did not benefit much in the mathematics lessons when equal opportunities to learn were provided. The present study reports on how learners with visual impairment perceive and engage with the teaching of mathematics in inclusive classrooms of Lesotho. The study follows a qualitative case study design using the framework of opportunity to learn (OTL) as the main theoretical resource through which conditions that facilitate effective teaching and learning of mathematics are examined. The article argues that what are often defined as opportunities to learn do not always translate into effective learning opportunities for learners with special educational needs. The opportunities to learn are mediated through the learners, who select what is and/or is not useful for them at a given point in time. Empowerment of both learners and teachers in the mediation of opportunities to learn will be a critical factor to ensure the success of interventions for inclusion in such mathematics classrooms.
\end{abstract}

Key words: curriculum, inclusive education, learners with visual impairment, mathematics education, opportunities to learn. 


\section{INTRODUCTION}

Inclusive education has caught the attention of educational systems around the globe and triggered interest among many educational researchers. Inclusive education stretches beyond just providing access for learners with special educational needs to regular schools (Mitiku et al., 2014). It is a dynamic process that is constantly evolving which might bring differing outcomes when applied in different contexts (Mariga et al., 2014). Erkilic and Durak (2013) considered inclusion as an approach intended to provide equal opportunities for all learners with diverse learning needs within regular schools, while Ainscow and César (2006) viewed it as an approach aimed to create educational opportunities for learners with special educational needs within regular school settings.

Inclusive education practices are perceived to have the potential for promoting learning that can lead to positive outcomes in terms of learner achievement (Agunloye \& Smith, 2015; Dyson et al., 2004). However, successful implementation of inclusive education depends on satisfying certain conditions. Erkilic and Durak (2012) argued that inclusive education practices require, among other things, "comprehensive institutional restructuring" as that can result in generating a conducive learning environment for learners. It should also be taken into consideration that the realisation of inclusion might not only demand the development of a curriculum that could cater for learners' diverse learning needs (Erkilic \& Durak, 2012). It would also necessitate the restructuring of pedagogical approaches (Ahmad, 2015). This concurs with the view held by Mariga et al. (2014) that inclusive education necessitates change of "attitudes, behaviours, teaching methods, curricula and environment to meet the needs of all children" (p. 27).

Das (2021) specifically focused on inclusive mathematics education. He contended that teachers are expected to be aware of learners' different educational needs in mathematics classrooms, with the purpose of offering them appropriate academic support. Das (2021) argued that this can be demanding as it calls for competent teachers with a clear understanding of practices that can best address diverse needs of learners. Apt teachers for this are those with a strong knowledgebase and skills that would enable them to transform their classroom practices in such a way that creates "rich learning opportunities" (Das, 2021, p. 1).

Durmuş and Ergen (2021) pointed out that inclusion is very important for improving the self-confidence of learners with special educational needs. Their study found that participating teachers were using a variety of teaching methods, which include demonstration, groupwork and activities such as games/plays/drama, in the mathematics classroom. However, time constraint did not permit them to assign individual activities to learners. Hence, additional time was needed for giving learners opportunity to engage in individual activities. In that regard, 
break sessions were often compromised for individual support, which took place in the supportive education room instead of mathematics class.

It is against this background that the present study aims at exploring factors that can improve mathematics teaching and learning in inclusive classrooms in a manner that favours learners with visual impairment. The discussions in this article are primarily centred around visually impaired learners' experiences of learning mathematics in a regular school setting.

The paper starts by reviewing pertinent literature that delineates the empirical focus of the study with the purpose of identifying gaps. It also provides a discussion focusing on a curriculum for inclusive education. The issue of visually impaired learners' experiences in regular school settings, which is central to this paper, is also discussed. Furthermore, arguments about the academic potential of learners with visual impairment are explored. After that, the conceptual framework and rationale for its selection are explained.

Subsequently, an explanation of the research methodology used is provided, including the approach and the design employed, sampling designs and procedures, as well as the ways in which validity, credibility, and reliability of the instruments were enhanced. The manner in which data were collected and analysed is presented, as well as the ethical guidelines that were adhered to in conducting the study. Thereafter, interpretation and discussions of the findings, including their significance and implications, follow. More so, the limitations of the study are stated and then conclusions are drawn and recommendations made. The paper ends by suggesting areas worthy of consideration in future studies.

\section{LITERATURE REVIEW}

Literature has consistently indicated that learners with visual impairment show relatively low academic achievement in mathematics (Beal \& Shaw, 2008). This can result in widening the achievement gap between these learners and their sighted peers (Ukeli \& Akem, 2013) when they are taught mathematics in inclusive classrooms. Visual impairment can affect learning as it may result in "a generally slow pace of work, which can only be improved to a limited extent with the help of technical aids" (Bartz, 2020, p. 223). Different degrees of visual impairment may differently affect how learners engage in classroom activities; for example, Braille readers may require more time to read mathematical expressions than learners who use print (Van Leendert et al., 2019).

Another issue that emerges from the literature is that learners who have coexistence of visual impairment and learning difficulties would be characterised by low academic performance in mathematics. It is unarguable that among learners with visual impairment there are those with learning difficulties in subjects such as mathematics. Nonetheless, considering 
all learners with visual impairment as having learning difficulties would be a misconception. For learners with visual impairment, learning difficulties have always been confused with visual impairment in cases where they coexist (Jones et al., 2015). Jones et al. (2015) recommended that a teacher should undertake prior assessments to diagnose a learner's actual condition as that could help when selecting an appropriate instructional intervention strategy. Thus, effective classroom-based support can advance learners' competences that enable them to confidently exert greater effort to attain outcomes similar to those of their sighted peers (Jones et al., 2015).

Research has shown that learners with visual impairment encounter a lot of challenges when learning some mathematics topics that involve visual content, including statistics and geometric-figure representations (Gorlewicz et al., 2020). Gorlewicz et al. (2020) found that it can sometimes be a challenge for learners with visual impairment to create "a mental image of the [geometric] shape due to the amount of information" (p. 24) that they are expected to memorise. Some studies have shown that early intervention of appropriate graphic teaching methods could enable learners with visual impairment to cognitively access mathematics content with graphics (Zhang \& Malasig, 2016).

It is widely reported that learners with visual impairment have a potential to attain improved academic scores (Shahed et al., 2016), especially when conditions that favour their learning are all met. Wieckert's (2021) study revealed that there is no significant difference in the self-concept development of learners regardless of whether they are visually impaired or not. The findings of the study also showed that when learners are engaged in activities that require them to gauge their competences, that enables them to build a realistic self-concept. Wieckert (2021) encouraged teachers to create enabling environments for learners to rate their own mathematics competences. It is reported that this approach has helped teachers to prepare lessons that are more inclined to the use of various bodily senses instead of focusing on visual learning methods only. Evidently, variation of the teaching methods not only benefits learners with visual impairment, but all learners in the inclusive classroom (Wieckert, 2021).

Gervasoni and Peter-Koop (2020) posited that while there are international pressures compelling for realisation of inclusive education, there is little published research focusing specifically on inclusive mathematics education in schools. Though teachers are expected to provide high-quality inclusive mathematics education that enables all learners to thrive, achieving this still remains a challenge for them. Rudinger (2020) identified the research gap in literature by indicating that the issue of best practices for instruction is not adequately addressed in educational research that involves learners with visual impairment. In view of this, 
the paper aims at addressing this gap by undertaking an investigation on how learners with visual impairment construct opportunities to learn in inclusive classrooms.

\section{DESCRIPTION OF OPPORTUNITY TO LEARN}

The framework of opportunity to learn (OTL) is the main theoretical resource through which learners' experiences of learning mathematics are explored. OTL is widely viewed as a multifaceted concept (Goos, 2014). However, some scholars view OTL along the lines of learners with special educational needs (Cawthon et al., 2012; Taub et al., 2017). Cawthon et al. (2012) stated that OTL might be concerned with raising learner engagement in inclusive settings, so as to ensure that learners with special educational needs access the general education curriculum. This framework might also be useful to assess learners' level of access to educational resources. Besides, OTL deals with learner placement in regular schools that practice inclusive education. A higher degree of OTL is not only determined by placement of learners with special educational needs in the least restrictive environment, but it should take into consideration that their needs are catered for through effective instructional approaches (Cawthon et al., 2012). Trevisan et al. (2020) mentioned the learning opportunities generated by the use of the classroom as a professional teaching and learning environment. Some of the opportunities that they took notice of included exploring ways that can promote learners' active involvement in discussions.

Taub et al. (2017) postulated that opportunities to learn for learners with special educational needs can be described in terms of improving access to "the intended, enacted, and assessed curricula through the planned curriculum that includes purposefully designed practices in classrooms" (p. 129). Among other issues that these researchers mentioned as having a potential to create opportunities to learn is provision of support and resources that can assist learners to actively participate in the classroom activities that facilitate learning (Taub et al., 2017). Sganzerla and Geller (2021) contended that assistive technology devices are the most important aids to facilitate early construction of number concept by learners with visual impairment at lower grades. These researchers held a strong view that these learners are as capable as sighted learners to learn mathematics concepts, especially when given the opportunity of accessing the assistive equipment.

Kohanová's (2010) study focused on OTL in relation to teaching of mathematics to learners with visual impairment in inclusive classrooms. She emphasised the importance of the use of technology for learners with visual impairment to learn mathematics. She argued that the use of information technologies can lead to improved educational opportunities for learners with visual impairment, so that they can "handle mathematical expressions quickly and 
efficiently in the same way as their sighted classmates" (p. 8). Chabongora and Jita (2013, p. 173) argued that "a better understanding of the OTL mathematics lies in the examination of what goes on during the teaching and learning of mathematics in the classroom". Suurtamm et al. (2016) perceived that it is through assessment that learners can develop understanding of mathematics. These researchers were of the view that teachers should employ a wide range of assessment strategies that can create more opportunities for learners to demonstrate their learning.

This discussion shows that previous researches on OTL used the classroom as their unit of analysis. Besides, OTL is viewed by many educational researchers as a teacher-dependent variable that mainly focuses on instructional practice.

\section{RESEARCH METHODOLOGY}

This paper reports on a qualitative case study conducted in two regular high schools accommodating learners with visual impairment. The choice of this design was influenced by its benefit of enabling an in-depth exploration of the research questions and which can as well generate rich data (Gustafsson, 2017). The research population comprised visually impaired learners within the targeted classroom, with specific attention to the secondary level of schooling. Detailed information was gathered about the experiences of individual learners with visual impairment, each considered as a distinct case. Two major sets of data were collected in the course of study. The major part of the data was gathered through the narratives of visually impaired learners in Grades 8 and 9 and direct observations of mathematics lessons were used for triangulation.

The data generated from transcripts of narrative interviews for each of the two cases were coded and arranged into themes that emerged from the evidence. Basically, each of the two cases was explored and analysed independently and, later on, comparisons were made in order to find similarities and differences.

Ethical issues were adhered to before and during the investigation. We followed appropriate procedures to seek clearance before commencement of data collection. The focus of ethics was more generally on protecting the identity of participants, considering the sensitivity of the research as it involved vulnerable groups. We were also expected to ensure that anything that might subject the participants to endangering incidents was avoided (Flick, 2009; Willig, 2013). 


\section{PRESENTATION AND DISCUSSIONS OF THE RESEARCH FINDINGS}

This paper presents data with respect to how Ketsahalo and Pheello (research participants) engaged with the teaching of mathematics in inclusive settings. Both participants are partially sighted learners. Their visual impairment condition has made them less effective when participating in classroom activities, especially those activities that require a sense of vision. They therefore also have a challenge when reading small font or reading from a chalkboard. Their narrative stories provide a sense of what kind of opportunities to learn, if any, their mathematics teachers created during mathematics lessons. The focus is also on how these learners with visual impairment made use of the available opportunities.

\section{Ketsahalo's story on the teaching of mathematics in his classroom}

Ketsahalo narrated how his mathematics teacher conducted the lessons in his classroom, by stating that: "She starts by introducing a certain mathematics concept and then gives us classwork." Ketsahalo provided details of how this was done in the following way:

Our mathematics teacher gives us an example first. That example makes us understand the concept. If you clearly understand how the example is done, you know exactly what to expect in the exercises from the textbook given as classwork.

Data demonstrated that the teacher usually provided examples before giving classwork. Ketsahalo believed that the examples helped him to develop a better understanding of the concept being taught, since he refers to them as he works on the exercises that are assigned. The teaching approach used in Ketsahalo's class can be likened to what Hodgen et al. (2018) referred to as "explicit instruction".

It was evident that the teacher taught mathematics in what Gallagher et al. (2017) referred to as "traditional form of instruction". The teacher seemed to prefer writing on the chalkboard when teaching mathematics in class. However, Ketsahalo seemed to encounter difficulty in reading some words written on the chalkboard. He narrated his version of the story regarding what transpired in one of the lessons: "When I was reading those words, I was not able to see clearly. Where it was written 'as' I was not sure whether it was 'as' because to me it appeared as 'are'."

This gives the impression that Ketsahalo confused some of the words, because he was unable to access the information displayed on the chalkboard clearly. Ketsahalo pointed out that: "I should be taught using visible handwriting and small cursive writing should not be used. This is because I often don't see what has been written." The implication here is that Ketsahalo's teacher wrote illegibly and that resulted in his difficulty in reading. Therefore, it is important to consider that teaching of mathematics to the visually impaired learner requires the teacher to use legible handwriting. 
When talking about the normal procedure that the teacher used when marking classwork, Ketsahalo said: "Your book gets marked when you have got correct answers. When you have incorrect answers, you are guided as to how you can approach the task. After that, I make some corrections and I resubmit." On the issue of whether his work on mathematics always gets marked, Ketsahalo stated: "When I get incorrect answers, I make corrections. But sometimes we would be told that the time is up; as a result, I would not be able to resubmit in that case." This statement shows that there are instances when Ketsahalo fails to get his work assessed. In that case, it would be difficult for him to discern his level of understanding of the concept being taught. He talked about the time he normally takes to complete a task in mathematics: "I sometimes finish mathematics tasks on time. But, when we are given too much work, I am not able to complete it in the stipulated time."

In light of this, it is clear that Ketsahalo could not finish the task within the stipulated time. Ultimately, his work on that task would not be marked, meaning that he might be excluded from participating in the task on the basis of being slow when writing. This suggests that Ketsahalo might require more time than other learners to finish the tasks given. Jessup et al. (2017) mentioned this factor as one of the challenges that often prevent visually impaired learners to complete the school curriculum. These researchers emphasised that the value of time should be respected, as it is very important for the visually impaired learners to maintain academic parity with their sighted peers. Aside from this, Ketsahalo's poor sight impacted on his copying information in the textbook accurately, as he explained:

I sometimes get wrong answers, because I write incorrect things from the textbook. I am trying my best to copy properly from the textbook. [...] Even when I write things from the textbook, they come out to be wrong. Now I am trying my best to closely look at the book in order to be able to copy them properly.

The evidence reflects that Ketsahalo's level of vision made it difficult for him to copy accurately from the textbook and that led him to get unexpected answers. Evidently, Ketsahalo took too long to complete a task given by the teacher, and his slow pace made him fall behind with his schoolwork. This is consistent with scholarship that shows that a visually impaired learner can take longer than the stipulated time to complete a task (Bardin \& Lewis, 2008). These researchers found that even capable learners with visual impairment can also encounter a challenge of keeping up with the pace of the lesson.

Based on the evidence presented, it can be concluded that Ketsahalo's mathematics teacher provided him minimum opportunities to learn in class. The teacher seemed to prefer using the chalk-and-talk teaching method, which has detrimental effects on learners' performance and attitude towards mathematics (Gallo-Toong, 2020). Opie et al. (2017) also 
acknowledged that learners with visual impairment encounter challenges in mathematics classrooms, which include lack of teacher preparation and ineffective teaching methods that often involve chalkboard use for solving examples. Taking into consideration that learners often have a negative reaction towards mathematics, Hill et al.'s (2020) study considered understanding learner wellbeing in mathematics education as an important aspect that can lead to improvement of learners' experiences in terms of how they perceive and engage in mathematics instructional practices. Mazana et al. (2019) shared similar sentiments and further argued that learners' performance in mathematics depends on whether they enjoy the subject or not, as well as their attitude towards it. These researchers argued that learners' attitude should not be considered as the only factor influencing their performance in mathematics. Another factor that can lead to unfavourable outcomes in assessment is the teacher's instructional practices, which tend to be didactic in nature.

\section{Pheello's story on the teaching of mathematics in his classroom}

Pheello shared his experience on how his mathematics teacher approached a newly introduced topic, by saying:

When he [mathematics teacher] is about to start a new topic, he gives us notes. He thinks we are taking them, but I never take them. I listen very attentively. I only listen to important elements that would be required when I attempt to answer a specific question. I know very well that I would not be required to give a definition of something in mathematics.

What can be learned from this extract is that even though the teacher gave notes to learners when introducing a new topic, Pheello's remark suggests that he did not copy them. His comment indicates that he seemed to listen only to what he considered useful when answering a particular question and disregarded some information he considered irrelevant.

Pheello was asked whether his mathematics teacher made an effort to ensure that his handwriting is legible to him on the chalkboard during lessons. His response was: "It's not with all teachers that I can see information displayed on the chalkboard. [...] I am able to read maths and geography". Pheello's statement demonstrates that his vision still allowed him to read what his teacher had written on the chalkboard. This rules out the possibility that he was not writing notes due to the illegible handwriting. It suggests, instead, that he might be making conscious choices about what he considers relevant or not.

Aside from relying heavily on his sense of hearing, Pheello appeared to be dependent on his memory. This had a likelihood of posing a challenge of accuracy when he produced written tasks, as he indicated that: "If I incorrectly memorise the example, I would get incorrect 
answers." He further explained that: "Last year, I relied more on memorising things. This year, we dealt with many topics that I didn't have a clear understanding of."

This suggests that memorisation plays an important role in Pheello's learning of mathematics concepts. He seemed to be aware that his success depended on memorising correct information. However, data showed that memorisation did not help him deal with topics that he found challenging. Memorisation, while not encouraged by scholars, seemed to be somewhat important for this visually impaired learner. The research conducted by Beal and Shaw (2008) showed that visually impaired learners rely on memory for dealing with word problems, accessed through an audio device. However, these researchers argued that learners with severe visual impairment encountered challenges when dealing with higher order tasks. This demonstrates that there are some instances when the use of memory becomes unhelpful to learners with visual impairment.

Pheello was asked whether the teacher used strategies catering for his educational needs during the lesson. He addressed the question by saying: "My teacher is highly competent in teaching learners who are visually impaired." Pheello justified his teacher's competence when he stated that: "I think you noticed that he would be writing and talking at the same time." This was evident in the two lessons observed. For example, during one of the observed lessons, the teacher continued with the lesson as captured in the following segment.

Teacher: So, today we are coming to deal with multiplication of decimal fractions or numbers. (He writes the statement on the board as he speaks. He repeats the same statement twice.) [...] [W]e are going to highlight on what is called decimal places (He writes that on the board). Like you highlighted earlier when you are adding and subtracting decimal numbers, you have place value. But when we add and subtract, we make sure that we add and subtract only numbers that fall under the same place. Akere re ile ra lumellana? [Is that what we agreed on?]

Learners Yes, sir.

(in

unison):

Teacher: Even with this one, we have to get a highlight of what is called decimal places. For example, Sefatela (not a real name) refreshed our minds with the place values that we have. And you reminded us that we have units, tens, hundreds, hana ke efeng moo? [What should be here?] (He lists them on the board.)

Learner: Thousands.

Teacher: (He repeats after the learner) Thousands, and so on. You can have a decimal 
point, and beyond a decimal point we have other place values, which are tenths, hundredths, thousandths, and so on. (He writes all these on the board as he speaks.)

The vignette demonstrates that the teacher was talking and writing at the same time during the lesson. This kind of teaching approach seemed to create better opportunities to learn for Pheello, as he could access information through listening and reading from the chalkboard. This resonates with the view that advances that teachers should be cognisant of the modalities of learners and try to reach each one of them regardless of their differing learning styles (Furner et al., 2005). Elçi's (2017) research revealed that teachers' content knowledge is important for assisting learners as it enables them to use diverse representation of mathematical knowledge and give appropriate examples.

Pheello's teacher made efforts to widen opportunities to learn during mathematics lessons as he would be talking and writing at the same time. The discussion also shows that the teacher provided the learners with written notes when introducing a new topic. However, it appeared that Pheello may not have taken full advantage of the opportunities to learn provided by his teacher. Pheello seemed to depend more on his sense of hearing and memorisation. The fact that Pheello considered his mathematics teacher's handwriting as legible enough implies that he still had an opportunity to use his residual vision to access information displayed on the chalkboard. Nonetheless, he consciously decided to rely on memorising mathematics concepts that only help him to answer specific questions. He, however, co-constructed the aspects of mathematics that he wanted to learn, even though this can lead to minimisation of his opportunities to learn mathematics concepts. According to Van den Heuvel-Panhuizen (2019), learners' individual conceptions and experiences have to be respected and taken as points of departure for teaching and learning.

\section{CONCLUSION}

This article devoted special attention to the in-depth narratives of two learners with visual impairment. The narratives of the participants showed that the presence of learners with visual impairment in the classroom might not influence the teacher's normal instructional practices, including the teaching style and pace of a lesson. The observed teachers largely used traditional forms of instruction in mathematics lessons where the visually impaired learners were involved. Heckman and Weissglass (1994) stated that traditional teaching strategies in mathematics do not essentially benefit learners as they fail to stimulate interest and engage learners in purposeful activities. The findings show that even when opportunities to learn are made available to learners with visual impairment, they still have full control over the selection 
of opportunities that they consider helpful to them. The data revealed that Pheello seemed to regulate opportunities to learn in his learning of mathematics. On this basis, a conclusion that can be drawn is that learners with visual impairment are aware of ways of leveraging their learning and that also appears to influence their opportunities to learn in the inclusive mathematics classroom. Many current studies perceive OTL as a teacher-dependent variable that mainly focuses on instructional practice. This study further extends this knowledge by showing that OTL is also learner-dependent in the case of learners with visual impairment in Lesotho.

The sample size could be considered a limitation of this study. The cases discussed here are vulnerable members of society. The major challenge that was likely to emerge would be the reluctance of participants to divulge precise information. For example, if ever they had experienced discrimination before, there would be a little apprehension about the kind of treatment they would receive after disclosing some evidence. This paper was interested in finding out how visually impaired learners perceive and engage in the teaching of mathematics in the inclusive classroom. A possible challenge associated with this includes participants feeling that the researcher intruded into their private space, which they might regard as exposing their weaknesses. Cohen et al. (2007) highlighted that some issues in educational research might be sensitive and the researcher should always be cautious when dealing with them. In this study, we were able to be reflexive enough to represent the experiences of the cases studied in a balanced manner that did not seek to cause embarrassment, or even to unnecessarily embellish them in any way.

The fact that the observed teachers used strategies that treated all learners as if they were sighted illustrates their lack of capacity and exposure in terms of teaching learners with visual impairment in inclusive classrooms. Based on this, there is a need to empower teachers with the relevant skills for teaching mathematics to learners with diverse learning needs. For them to efficiently perform their mandate as expected, an intensive in-service programme can be conducted. There is also a need for the Ministry of Education and Training to develop an adaptive curriculum guiding teachers on effective strategies to teach mathematics to learners with educational needs, especially those with visual impairment. Future studies may explore approaches to teaching mathematics that are aligned to the needs of learners with visual impairment. 


\section{REFERENCE LIST}

1. Agunloye, O. O., \& Smith, B. R. (2015). Effect of inclusive education on the performance of students in mathematics and English language: A school study. European Scientific Journal, 11(10), 211-219.

2. Ahmad, F. K. (2015). Challenging exclusion: Issues and concerns in inclusive education in India. Researchpaedia, 2(1), 15-32.

3. Ainscow, M., \& César, M. (2006). Inclusive education ten years after Salamanca: Setting the agenda. European Journal of Psychology of Education, 21(3), 231-238.

4. Bardin, J. A., \& Lewis, S. (2008). A survey of the academic engagement of students with visual impairments in general education classes. Journal of Visual Impairment \& Blindness 102(8), 472-482.

5. Bartz, J. (2020). All inclusive?! Empirical insights into individual experiences of students with disabilities and mental disorders at German universities and implications for inclusive higher education. Education Sciences, 10(9), 223-248.

6. Beal, C. R., \& Shaw, E. (2008). Working memory and math problem solving by blind middle and high school students: Implications for universal access. Technology and Teacher Education Annual, 19(8), 5011-5016.

7. Cawthon, S. W., Beretvas, S. N., Kaye, A. D., \& Lockhart, L. L. (2012). Factor structure and opportunity to learn for students with and without disabilities. Education Policy Analysis Archives, 20(41), 1-30.

8. Cohen, L., Manion, L., \& Morrison, K. (2007). Research Methods in Education, $6^{\text {th }}$ edition. New York: Routledge.

9. Chabongora, B. N., \& Jita, L. C. (2013). Opportunities to learn (OTL) grade-10 algebra in three South African catholic secondary schools. Journal of Educational Studies 12(1), 172-188.

10. Das, K. (2021). Inclusive mathematics education in classroom practice. Shanlax International Journal of Arts, Science and Humanities, 8(3), 1-5.

11. Durmuş, M. E., \& Ergen, Y. (2021). Experience of primary school teachers with inclusion students in the context of teaching mathematics: A case study. International Journal of Progressive Education, 17 (1), 172-195.

12. Dyson, A., Farrell, P., Polat, F., Hutcheson, G., \& Gallannaugh, F. (2004). Inclusion and pupil achievement. London: Department for Education and Skills.

13. Elçi, A. N. (2017). Students' attitudes towards mathematics and the impacts of mathematics teachers' approaches on it. Acta Didactica Napocensia, 10(2), 99-108. 
14. Erkilic, M., \& Durak, S. (2013). Tolerable and inclusive learning spaces: An evaluation of policies and specifications for physical environments that promote inclusion in Turkish primary schools. International Journal of Inclusive Education, 17(5), 462-479.

15. Flick, U. (2009). An introduction to qualitative research, 4th edition. London: Sage.

16. Furner, J. M., Yahya, N., \& Duffy, M. L. (2005). Teach mathematics: Strategies to reach all students. Intervention in School and Clinic, 41(1), 16-23.

17. Gallagher, T. L., Bennett, S., Keen, D., \& Muspratt, S. (2017). Examining learner engagement strategies: Australian and Canadian teachers' self-report. Teacher Education and Special Education 40(1), 51-64.

18. Gallo-Toong, N. (2020). The extent of use of concrete-representational-abstract (CRA) model in mathematics. International Journal for Research in Mathematics and Statistics $6(5), 1-25$.

19. Gervasoni, A., \& Peter-Koop, A. (2020). Inclusive mathematics education. Mathematics Education Research Journal, 32, 1-4. https://doi.org/10.1007/s13394-020-00315-0

20. Goos, M. (2014). Creating opportunities to learn in mathematics education: A sociocultural perspective. Mathematics Education Research Journal, 26(3), 439-457.

21. Gorlewicz, J. L., Tennison, J. L., Uesbeck, P. M., Richard, M. E., Palani, H. P., Stefik, A., Smith, D. W., \& Giudice, N. A. (2020). Design guidelines and recommendations for multimodal, touchscreen-based graphics. ACM Transactions on Accessible Computing (TACCESS), 13(3), 1-30.

22. Gustafsson, J. (2017). Single case studies vs. multiple case studies: A comparative study. The Qualitative Report, 20(3), 21-26.

23. Heckman, P. E., \& Weissglass, J. (1994). Contextualized mathematics instruction: Moving beyond recent proposals. For the Learning of Mathematics, 14(1), 29-33.

24. Hill, J. L., Kern, M. L., Seah, W. T., \& Van Driel, J. (2020). Feeling good and functioning well in mathematics education: Exploring students' conceptions of mathematical well-being and values. ECNU Review of Education, 1-27. https://doi.org/10.1177/2096531120928084

25. Hodgen, J., Foster, C., Marks, R. \& Brown, M. (2018). Evidence for review of mathematics teaching: Improving mathematics in key stages two and three: Evidence review. London: Education Endowment Foundation.

26. Jessup, G., Bundy, A. C., Broom, A., \& Hancock, N. (2017). The social experiences of high school students with visual impairments. Journal of Visual Impairment, \& Blindness 111(1), 5-19. 
27. Jones, B. A., Smith, H. H., Hensley-Maloney, L., \& Gansle, K. A. (2015). Applying response to intervention to identify learning disabilities in students with visual impairments. Intervention in School and Clinic 51(1), 28-36.

28. Kohanová, I. (2010). The ways of teaching mathematics to visually impaired students. Bratislava, Slovakia: Comenius University.

29. Mariga, L., McConkey, R., \& Myezwa, H. (2014). Inclusive education in low-income countries: A resource for teacher educators, parent trainers and community development workers. Oslo: Atlas Alliance.

30. Mazana, Y. M., Suero Montero, C., \& Olifage, C. R. (2019). Investigating students' attitude towards learning mathematics. International Electronic Journal of Mathematics Education, 14(1), 207-231.

31. Mitiku, W., Alemu, Y., \& Mengsitu, S. (2014). Challenges and opportunities to implement inclusive education. Asian Journal of Humanity, Art and Literature, 1(2), 119-136.

32. Opie, J., Southcott, J., \& Deppeler, J. (2017). "It helps if you are a loud person": Listening to the voice of a school student with a vision impairment. The Qualitative Report, 22(9), 2369-2384.

33. Rudinger, B. (2020). Nonvisual access to print \& its barriers: A review of the literature. Forum Pedagogiczne, 10(2), 29-43.

34. Sganzerla, M. A. R., \& Geller, M. (2021). Study on the construction of early mathematical concepts involving visually impaired students and assistive technology. Revista Inclusiones, 8(1), 419-447.

35. Shahed, S., Ilyas, Z., \& Hashmi, A. M. (2016). Academic performance, self efficacy and perceived social support of visually impaired students. Annals of King Edward Medical University, 22(1), 72-77.

36. Suurtamm, C., Thompson, D. R., Kim, R. Y., Moreno, L. D., Sayac. N., Schukajlow, S., Silver, E., Ufer, S., \& Vos, P. (2016). Assessment in mathematics education: Largescale assessment and classroom assessment. Springer.

37. Taub, D. A., McCord, J. A., \& Ryndak, D. L. (2017). Opportunities to learn for students with extensive support needs: A context of research-supported practices for all in general education classes. The Journal of Special Education, 51(3), 127-137.

38. Trevisan, A. L., Ribeiro, A. J., \& Ponte, J. P. D. (2020). Professional learning opportunities regarding the concept of function in a practice-based teacher education program. International Electronic Journal of Mathematics Education, 15(2), 1-14. 
39. Ukeli, V. T., \& Akem, I. A. (2013). Parental role in mathematics achievement of visually impaired students in Benue State. Journal of Educational and Social Research, $3(5), 25-36$.

40. Van Leendert, A., Doorman, M., Drijvers, P., Pel, J., \& Van der Steen, J. (2019). An exploratory study of reading mathematical expressions by Braille readers. Journal of Visual Impairment \& Blindness, 113(1), 68-80.

41. Van den Heuvel-Panhuizen, M. (2020). National reflections on the Netherlands didactics of mathematics: Teaching and learning in the context of realistic mathematics education. Utrecht: Springer Nature.

42. Wieckert, S. (2021). Inclusive education and the development of the self-concept concerning mathematical competences. Systemics, Cybernetics and Informatics, 19(1), 116-125.

43. Willig, C. (2013). Introducing qualitative research in psychology, 3rd edition. Berkshire: McGraw-Hill Education.

44. Zhang, D. A., \& Malasig, J. A. (2016). Review of literature: Mathematics instruction for students with visual impairments. Journal of Childhood \& Developmental Disorders, 2, $1-4$.

Copyright (C) 2022 Published by Khachatur Abovyan Armenian State Pedagogical University \& the Authors

The article submitted and sent to review: 10.09.2021

Accepted for publication: 11.01.2022 